\title{
Path Following of a Water-Jetted USV Based on Maneuverability Tests
}

\author{
Junmin Mou ${ }^{1}$, Yangying $\mathrm{He}^{2}{ }^{2}$, Benren Zhang ${ }^{1}$, Shixuan $\mathrm{Li}^{3}$ and Yong Xiong ${ }^{1, *}$ \\ 1 Hubei Key Laboratory of Inland Shipping Technology, Wuhan University of Technology, Wuhan 430063, \\ China; moujm@whut.edu.cn (J.M.); zhangbenren@whut.edu.cn (B.Z.) \\ 2 School of Navigation, Wuhan University of Technology, Wuhan 430063, China; heyangying@whut.edu.cn \\ 3 Department of Aerospace and Mechanical Engineering, University of Southern California, Los Angeles, \\ CA 90017, USA; shixuanl@usc.edu \\ * Correspondence: xyong@whut.edu.cn; Tel.: +86-027-87651862
}

Received: 22 March 2020; Accepted: 7 May 2020; Published: 16 May 2020

check for updates

\begin{abstract}
Due to the high propulsive efficiency and better maneuverability under high speed, the water-jetted unmanned surface vehicle (USV) is widely studied and used. This paper presents complete maneuvering tests and control algorithm designed for a twin water-jetted USV model. Firstly, a wireless network control platform is established, and maneuvering tests, for instance, an inertia test, zig-zag test and turning test, are carried out to verify the maneuverability of the USV. In light of the complexity and uncertainty of ship sailing and ship handling, the Human Simulated Intelligent Control (HSIC) method is utilized to optimize the response time, accuracy and robustness of the controller. Finally, for the path following and track rectification part, a Line of Sight (LOS) algorithm is improved and proved practicable with triangle/square path tests. The proposed intelligent navigation algorithm specially designed for matching with the control methods, showing satisfactory improvements on the motion control and path following of the specific USV.
\end{abstract}

Keywords: water-jetted USV; maneuvering; wireless network control platform; model tests; HSIC algorithm; path following

\section{Introduction}

Unmanned surface vehicles (USV) are vehicles that operate on the surface of the water without a crew on board. In terms of the propulsion modes, propelled and water-jetted USVs are normally experienced. Water-jetted propulsion is characterized with better propulsion efficiency [1], maneuverability and anti-cavitation performance [2,3], and has attracted more attention than propeller propulsion, which is suitable for the unmanned craft.

With the development of intelligent control, information communication technology, satellite positioning and navigation systems, water-jetted USVs are of great significance in the military throughout the world [4]. For example, the 'Inspector' [5], the 'Stingary' [6], the 'Owl MK II' [7] and the 'Silver Marlin' [6] are very good at tasks of mine clearance, anti-submarine, sea interception, search and rescue. In addition, water-jetted USVs like 'AutoCat' [8], 'UMV-O' [9], 'HaiTeng 1' [10] and 'JingHai 1' [11] play an extremely important role in civil fields, such as resource exploration, hydrography [12], channel measurement and atmosphere exploration [13].

Since maneuverability is one of the basic performances of USV [14], good maneuverability is important in safe and economic navigation. Li et al. (2008) [15] analyzed the thrust and torque of the pump and the split duct deflector under different working conditions, and based on the ship maneuvering mathematical model MMG, the movement caused by twin water-jet propulsion units was simulated. The results showed that the steering device was with excellent maneuvering 
performance, and could be applied as a controller to steer the ship ahead, astern and to any other condition. Huang (2015) [16] investigated the surface stress of USV and divided it into inertia type of fluid power, viscous fluid power, stern drive propeller power, wind interference force, wave and current effect. The corresponding mechanical model was established for each force and, finally, a six degrees of freedom (6-DOF) model of USV was presented. Then, the turning test and the zig-zag test were conducted under normal sea conditions. Using the least-squares algorithm, the parameters of the response model for 'LANXIN' USV were identified. Ma et al. (2015) [17] investigated the maneuverability indexes of $\mathrm{K}$ and $\mathrm{T}$ involved with a self-controlled USV through the inertia test, zig-zag test and turning test, the steering quality indexes were found decreasing with the increases of the steer angles, and the value of $\mathrm{K}$ changing more smoothly in the process.

The control system is a vital issue in the research and development of USV. To solve the problems caused by the changeable navigation environment and hydrological conditions of USV, the uncertainty of ship dynamic model, random environmental interference and inaccurate measurement information, some scholars put forward the motion control theory of 'humanoid intelligence' into practice. It has been applied to the field of ship control. Zhang et al. (2018) [18] designed a controller by using a human-simulated intelligent PID (proportion-integral-derivative) algorithm, and the heading control was realized. $\mathrm{Hu}$ (2017) [19] designed an automatic driving system based on HSIC and achieved an accurate path track of an unmanned ship combined with the humanoid control strategy. Zha et al. (2006) [20] simulated the motion control of an underwater robot and achieved a good result. Considering that the system could simulate human control decision-making ideas, it can work in actual engineering applications with a high performance of robustness, accuracy and rapidity.

Path following is a fundamental problem for USVs [21,22], which means the vessels have to follow a predefined path without time constraints [23], and it is generally accepted that the Line of Sight (LOS) guidance law is able to achieve path following. For the purpose of improving the adaption of the controlling system, Liu et al. [24] introduced the longitudinal path following error in Serret-Frenet coordinate frame into LOS, which proved to be of great effectiveness. Based on a modified two-dimensional LOS with integral action and two feedback controllers, Caharija et al. [25] implemented an auxiliary system to reduce the influence of wave drift, wind load and current in the ocean. Lekkas et al. [26] optimized the LOS method with a time-varying equation for the lookahead distance, which shortened the response time for path reselecting, and strengthened the robustness of the algorithm. The remainder of this paper is organized as follows: Section 2 describes the 3-DOF ship movement equation and obtains reliable execution parameters through experiments. Section 3 presents the system architecture, introduces HSIC control law, performs experiments, both in simulation and physical conditions, and illustrates the rule of autonomous navigation and presents experimental results of path following. Finally, Section 4 presents conclusions and future work.

\section{Materials and Methods}

Considering the motion characteristics of USV, an Abkowite model for 3-DOF maneuvering mathematical model, referred to as surge, sway and heave, is made. In Figure 1, inertial coordinates $\sum$, $O-X Y$, and body-fixed coordinates $\sum_{1}, O_{1}-X_{1} Y_{1}$ are used, and $\delta$ is the rudder angle. The kinematic equation relating velocity components in the inertial frame to those in the body frame is described as Equation (1), $X$ and $Y$ are the first derivative of $X, Y$ respectively, $\psi$ is the heading (yaw) angle, $(u, v)$ is the body-fixed velocities (surge and sway), and $r$ is the yaw rate.

$$
\left\{\begin{array}{l}
X=u \cos \psi-v \sin \psi \\
Y=v \sin \psi+u \sin \psi \\
\psi=r
\end{array}\right.
$$




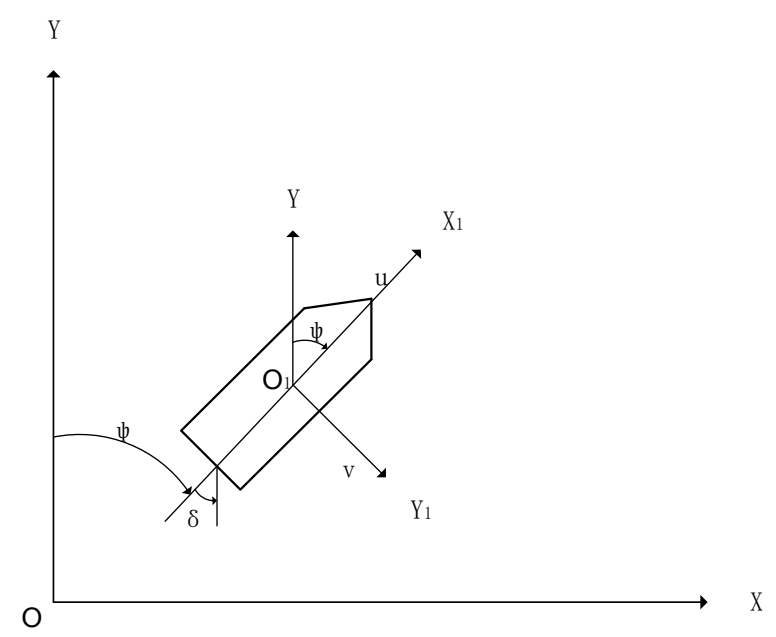

Figure 1. Coordinate system of ship.

To simplify the issue, the external disturbance caused by the environment is not taken consideration, the ship equations of motion can be written as Equation (2)

$$
\left[\begin{array}{ccc}
m-X_{u} & 0 & 0 \\
0 & m-Y_{v} & m x_{G}-Y_{r} \\
0 & m x_{G}-N_{v} & I_{z z}-N_{r}
\end{array}\right]\left[\begin{array}{c}
u \\
v \\
r
\end{array}\right]=\left[\begin{array}{l}
f_{1} \\
f_{2} \\
f_{3}
\end{array}\right]
$$

where:

$$
\begin{aligned}
f_{1} & =a_{1} u+a_{2} u^{2}+a_{3} v^{2}+a_{4} r^{2}+a_{5} r v+a_{6}\left(k \delta_{\max }(1-T)\right)^{2}+a_{7} u\left(k \delta_{\max }(1-T)\right)^{2} \\
& +a_{8} v\left(k \delta_{\max }(1-T)\right)+a_{9} u v\left(k \delta_{\max }(1-T)\right) \\
f_{2} & =b_{1} v+b_{2} r+b_{3} v^{2} r+b_{4} v u+b_{5} r u+b_{6}\left(k \delta_{\max }(1-T)\right)+b_{7} u\left(k \delta_{\max }(1-T)\right) \\
& +b_{8} u^{2}\left(k \delta_{\max }(1-T)\right)+b_{9} v\left(k \delta_{\max }(1-T)\right)^{2}+b_{10} v^{2}\left(k \delta_{\max }(1-T)\right)+b_{11}+b_{12} u+b_{13} u^{2} \\
f_{3} & =c_{1} v+c_{2} r+c_{3} v^{2} r+c_{4} v u+c_{5} r u+c_{6}\left(k \delta_{\max }(1-T)\right)+c_{7} u\left(k \delta_{\max }(1-T)\right) \\
& +c_{8} u^{2}\left(k \delta_{\max }(1-T)\right)+c_{9} v\left(k \delta_{\max }(1-T)\right)+c_{10} v^{2}\left(k \delta_{\max }(1-T)\right)+c_{11}+c_{12} u+c_{13} u^{2}
\end{aligned}
$$

where, $m$ is mass of USV, $\mathrm{kg} ; I_{z z}$ is the moment of inertia around the $\mathrm{z}$-axis, $\left(\mathrm{kg} \cdot \mathrm{m}^{2}\right) ; x_{G}$ is center of gravity of USV, $k$ is proportionality coefficient, which can be determined by simulation and tests, $\delta_{\max }$ is the maximum rudder angle, ${ }^{\circ} ; X_{u}, Y_{v}, N_{r}, a_{n}, b_{n}, c_{n}(\mathrm{n}=1-15)$ are the hydrodynamic derivatives.

For water-jetted USV, its power is provided by the reaction force of the water flow (Equation (4))

$$
T_{J}=\rho Q\left(v_{a}-v_{e}\right)
$$

where, $T_{J}$ is the thrust derived under the ideal condition, $\mathrm{N} ; \rho$ is the mass density of the fluid, $\mathrm{kg} / \mathrm{m}^{3} ; Q$ is the volume rate of flow through the water-jet, $\mathrm{m}^{3} ; v_{a}$ and $v_{e}$ denote the velocity of flow at outlet and inlet, $\mathrm{m} / \mathrm{s}$. $v_{e}=(1-\omega) v_{s}, v_{s}$ is the velocity of USV, $\mathrm{m} / \mathrm{s} ; \omega$ is the wake coefficient, $\omega=0.55 C_{b}-0.2, C_{b}$ is a square coefficient. The turning moment acting on the unmanned boat can be written as Equation (5)

$$
M_{p}=\frac{P_{D}}{2 \pi n}
$$

where, $M_{P}$ is propeller absorption torque, $(\mathrm{N} \cdot \mathrm{m}) ; P_{D}$ is the required shaft power of the jet pump, $\mathrm{W}$; $P_{D}=p_{s} \eta_{c}, p_{s}$ is the main engine power, $\mathrm{W} ; \eta_{c}$ is the shafting efficiency; $n$ is the rotational speed of the pump, $r$ /min. For the twin water-jets USV, the relationship between rudder angle and rotational speed can be written as Equation (6)

$$
\delta=k\left(1-n_{2} / n_{1}\right) \delta_{\max }
$$


where, $n_{1}$ is left motor speed, $\mathrm{r} / \mathrm{min} ; n_{2}$ is right motor speed, $\mathrm{r} / \mathrm{min}$.

Based on the above model, some ultimate operation conditions can be estimated, which is beneficial to design the constraint conditions during actual motion control and path planning. These constraints are used to improve the reliability and accuracy of course and track control. Therefore, the following constraints are established for autonomous navigation in reality:

(1) Constraints of Rotational Speed Rotation speed $n_{1} \subset[0,2500], n_{2} \subset[0,2500], \delta=k(1-T) \delta_{\max }$, $\delta_{\max }=20$, therefore $0.6 \leq T \leq 1.5$.

(2) Constraints of Heading Angle Deviation

$$
\left(\psi_{k g}-\psi_{i}\right)^{2} \leq a_{i}^{2}, i=1,2,3 \ldots n, k=1,2,3 \ldots s
$$

where, $k$ is the target point subscription, $i$ is real-time dynamic position subscription of USV, $\psi_{\mathrm{kg}}$ is reference heading angle of USV from starting point to target point, ${ }^{\circ} ; \psi_{i}$ is the real-time heading angle of USV, ${ }^{\circ} ; a_{i}$ is maximum deviation between reference heading angle and current heading angle of USV, ${ }^{\circ}$. By running tests, the specific relations between the rudder angle and rotational speed are shown in Table 1.

Table 1. Mapping relations between rudder angle and rotational speed.

\begin{tabular}{|c|c|c|c|c|c|}
\hline $\begin{array}{c}\text { Simulated } \\
\text { Rudder Angle }\end{array}$ & $\begin{array}{c}\text { Simulated } \\
\text { Cycle Radius }\end{array}$ & $\begin{array}{c}\text { Simulated } \\
\text { Speed }\end{array}$ & $\begin{array}{l}\text { Left Pump Rotational } \\
\text { Speed } n_{1} \text {-Right Pump } \\
\text { Rotational Speed } n_{2} \\
\quad(0-2500 \mathrm{r} / \mathrm{min})\end{array}$ & $\begin{array}{l}\text { Turning } \\
\text { Radius }\end{array}$ & Speed \\
\hline $5^{\circ}$ & $10.9 \mathrm{~m}$ & $3.0 \mathrm{~m} / \mathrm{s}$ & $1625 \mathrm{r} / \mathrm{min}-1500 \mathrm{r} / \mathrm{min}$ & $11.25 \mathrm{~m}$ & $3.37 \mathrm{~m} / \mathrm{s}$ \\
\hline $10^{\circ}$ & $9.5 \mathrm{~m}$ & $3.5 \mathrm{~m} / \mathrm{s}$ & $1775 \mathrm{r} / \mathrm{min}-1500 \mathrm{r} / \mathrm{min}$ & $9.63 \mathrm{~m}$ & $3.56 \mathrm{~m} / \mathrm{s}$ \\
\hline $15^{\circ}$ & $6.8 \mathrm{~m}$ & $3.5 \mathrm{~m} / \mathrm{s}$ & $1950 \mathrm{r} / \mathrm{min}-1500 \mathrm{r} / \mathrm{min}$ & $7.16 \mathrm{~m}$ & $3.74 \mathrm{~m} / \mathrm{s}$ \\
\hline $20^{\circ}$ & $5.2 \mathrm{~m}$ & $4.0 \mathrm{~m} / \mathrm{s}$ & $2150 \mathrm{r} / \mathrm{min}-1500 \mathrm{r} / \mathrm{min}$ & $5.51 \mathrm{~m}$ & $3.96 \mathrm{~m} / \mathrm{s}$ \\
\hline$-5^{\circ}$ & $12.8 \mathrm{~m}$ & $5.5 \mathrm{~m} / \mathrm{s}$ & $1950 \mathrm{r} / \mathrm{min}-2200 \mathrm{r} / \mathrm{min}$ & $13.46 \mathrm{~m}$ & $5.52 \mathrm{~m} / \mathrm{s}$ \\
\hline$-10^{\circ}$ & $11.1 \mathrm{~m}$ & $5.0 \mathrm{~m} / \mathrm{s}$ & $1775 \mathrm{r} / \mathrm{min}-2200 \mathrm{r} / \mathrm{min}$ & $11.64 \mathrm{~m}$ & $5.12 \mathrm{~m} / \mathrm{s}$ \\
\hline$-15^{\circ}$ & $8.5 \mathrm{~m}$ & $5.0 \mathrm{~m} / \mathrm{s}$ & $1625 \mathrm{r} / \mathrm{min}-2200 \mathrm{r} / \mathrm{min}$ & $8.93 \mathrm{~m}$ & $4.71 \mathrm{~m} / \mathrm{s}$ \\
\hline$-20^{\circ}$ & $5.9 \mathrm{~m}$ & $4.5 \mathrm{~m} / \mathrm{s}$ & $1550 \mathrm{r} / \mathrm{min}-2200 \mathrm{r} / \mathrm{min}$ & $6.12 \mathrm{~m}$ & $4.13 \mathrm{~m} / \mathrm{s}$ \\
\hline
\end{tabular}

The table illustrates that, when the speed is less than $4 \mathrm{~m} / \mathrm{s}, \delta=k_{1}\left(1-n_{2} / n_{1}\right) \delta_{\max }, \delta_{\max }=20$, $k_{1} \approx 3.3$, the USV turns left with $n_{1}=1500 \mathrm{r} / \mathrm{min}$ while it turns right with $n_{2}=1500 \mathrm{r} / \mathrm{min}$. Apart from that, when the speed is more than $4 \mathrm{~m} / \mathrm{s}, k_{2} \approx 2.0$, the USV turns left with $n_{1}=2200 \mathrm{r} / \mathrm{min}$, while it turns right with $n_{2}=2200 \mathrm{r} / \mathrm{min}$.

\section{Results}

The USV studied in this paper is $3 \mathrm{~m}$ long and $1.3 \mathrm{~m}$ wide with twin water-jets (Figure 2), the main parameters of the USV shown in Table 2.

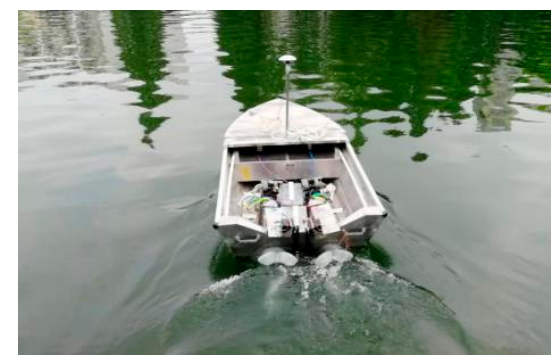

(a)

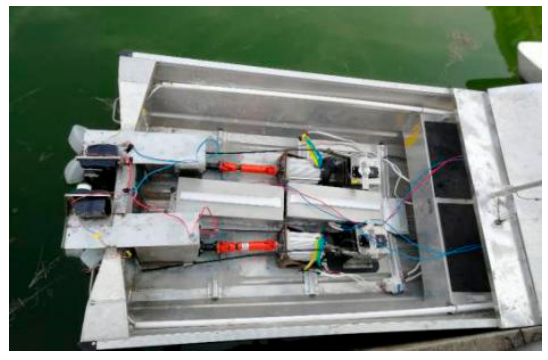

(b)

Figure 2. Twin water-jets water unmanned surface vehicles ((a): back view of USV; (b): top view of USV). 
Table 2. Particulars of the USV.

\begin{tabular}{cc}
\hline Items & Value \\
\hline Mass $(m)$ & $217.4 \mathrm{~kg}$ \\
Draft $(D)$ & $0.36 \mathrm{~m}$ \\
Rated speed $(n)$ & $2500(\mathrm{r} / \mathrm{min})$ \\
Maximum speed $(v)$ & $6.2(\mathrm{~m} / \mathrm{s})$ \\
Center of gravity $\left(X_{G}\right)$ & $0.23 \mathrm{~m}$ \\
Length $(L)$ & $3 \mathrm{~m}$ \\
Breadth $(B)$ & $1.3 \mathrm{~m}$ \\
\hline
\end{tabular}

\subsection{Construction of USV Control System Platform}

\subsubsection{Hardware Structure}

The power drive unit includes H-bridge dual-motor drive, which can drive $1000 \mathrm{~W}$ power load, with optocoupler isolation. The propulsion consists of two DC brush motors, and the control signal is provided by the analog signal pins of the microcontroller.

The control system of the USV covers two parts: hardware part is based on the micro control unit (MCU), including sensor components with functions of environment sensing and signal acquisition; software part includes signal processing, motion control, path planning algorithm, etc.

Hardware section: the unmanned boat control system depicted in Table 3, includes MCU; wireless network communication unit; driver unit and dynamic perception unit.

Table 3. System structure.

\begin{tabular}{cc}
\hline Function & Device \\
\hline Micro Control Unit (MCU) & STM32F103VET6 \\
Inertial Measurement Units (IMU) & MPU9250 \\
Navigation & GPS + digital compass \\
Communication & GPRS + Zigbee \\
Debugging & Zigbee \\
Others & SIM, antenna, motor controller \\
\hline
\end{tabular}

\subsubsection{Software Architecture}

The Web Server is built on China Unicom ECS (Elastic Compute Service). The link to the website is http://www.cheerstech.cn/system/. The design adopts the layered B/S software architecture. Only one browser needs to be installed on the client. SQL Server, Oracle, MySql, and other databases are installed on the server; the browser interacts with the database through Web Server.

The device establishes a long SOCKET connection with the server through the TCP protocol, so that the lower computer and the upper computer establish a stable data transmission channel for data uploading and downloading. The tool that is utilized includes the library of marker and distance, Baidu map API (http://api.map.baidu.com/api?v=2.0) is called for location display and path point setting of unmanned boats. Figure 3 shows the signal flow of the control processing. And other tools used in this paper can be seen as: http://api.map.baidu.com/library/MarkerTool/1.2/src/MarkerTool_min.js and http://api.map.baidu.com/library/DistanceTool/1.2/src/DistanceTool_min.js. 


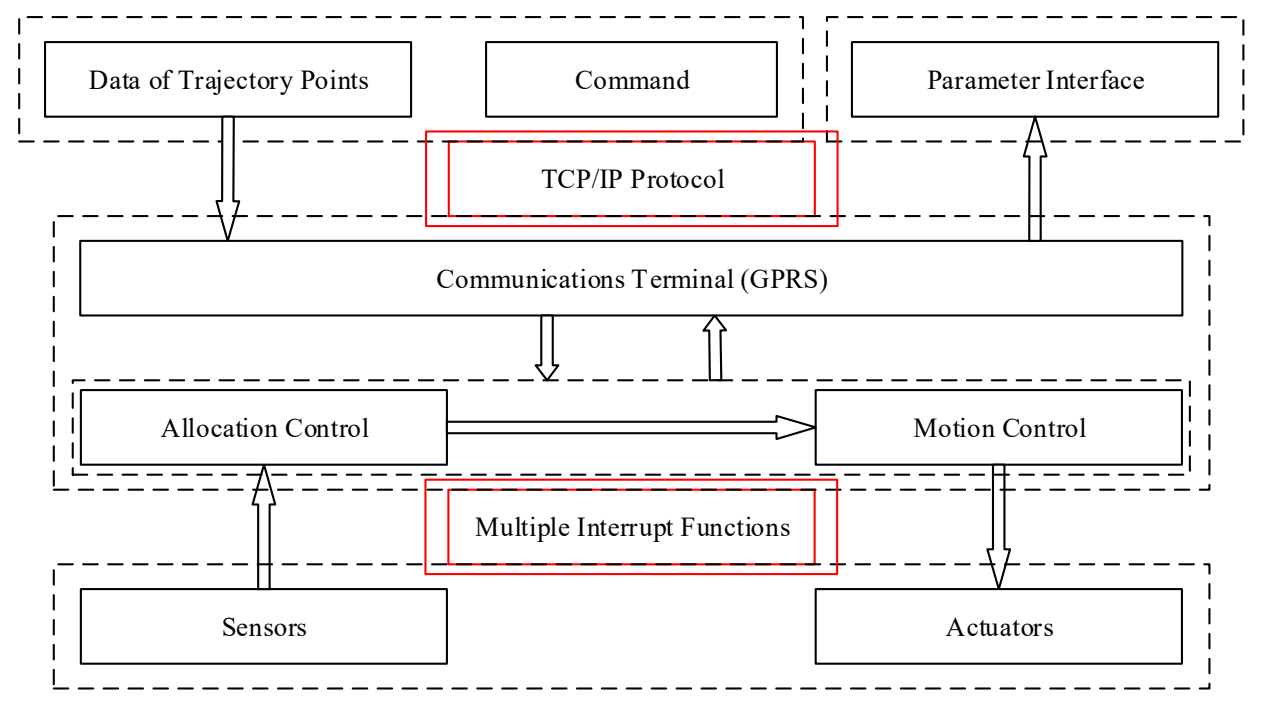

Figure 3. Signal flow.

\subsection{Maneuvering Test}

After establishing the mapping relationship between the rudder angle and rotational speed, based on these parameters, inertia test, zig-zag test and turning test were carried out to verify the maneuverability and applicability of the parameters of the USV.

\subsubsection{Inertia Test}

The inertia tests are consisted of two main parts, one is speed regulation test and the other one is stopping test. The experimental procedure is:

(1) First, set a coordinate for the twin water-jetted USV, along the direction of the berth of the water tank is the $X$ axis, and the direction perpendicular to the berth boundary is the $Y$ axis.

(2) Second, set the heading to positive $Y$ direction, and start the USV with an initial velocity of 4 knots (around $2 \mathrm{~m} / \mathrm{s}$ ), then send command to the USV to adjust the velocity to $10 \mathrm{knots}(5 \mathrm{~m} / \mathrm{s})$, activate the stopping command as the hull reaches the given speed, record the speed variations at $1 \mathrm{~Hz}$, when the ship is relatively motionless to the water, stop the execute.

(3) Finally, trim the heading to $\pm 10^{\circ}$ on Y-axis, and repeat procedure 2.

Figure 4 shows the speed-time curve of the inertia test carried out along positive Y direction, it takes the USV $6 \mathrm{~s}$ to reach the given speed (around 9 knots), and arounds $17 \mathrm{~s}$ to slide around $19 \mathrm{~m}$. And the velocity curve at $\pm 10^{\circ}$ course angles are illustrated in Figure $5 \mathrm{a}, \mathrm{b}$, respectively, it takes around $6 \mathrm{~s}$ to reach full speed, and $10 \mathrm{~s}$ to stop the ship from full speed, the stop stroke is approximately $29 \mathrm{~m}$ in both tests, while in $-10^{\circ}$ test (Figure $5 \mathrm{a}$ ) the achieved full speed is 9 knots $\left(10\right.$ knots set), in $+10^{\circ}$ test that is 10 knots with 10 knots commanded.

According to the maneuvering standards, stop stroke less than 8-20 times of length of all (LOA), namely 24-60 m, so it can be concluded that the USV has a good ability in terms of speed regulation and good maneuverability. 


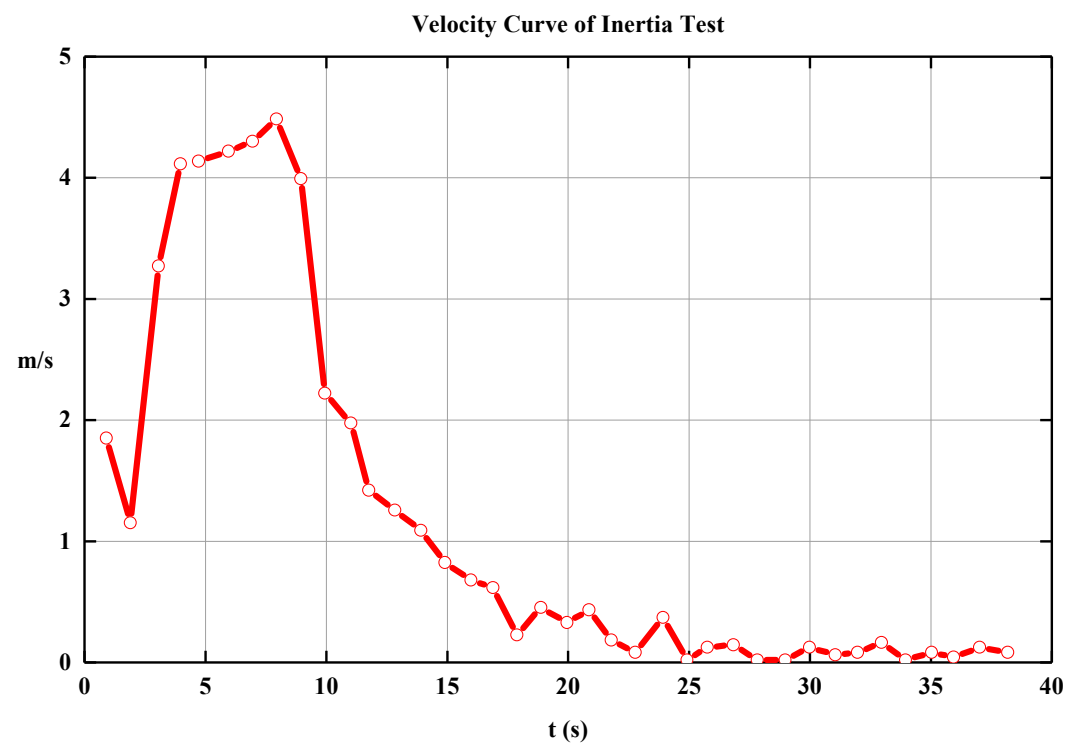

Figure 4. Velocity curve of inertia test.

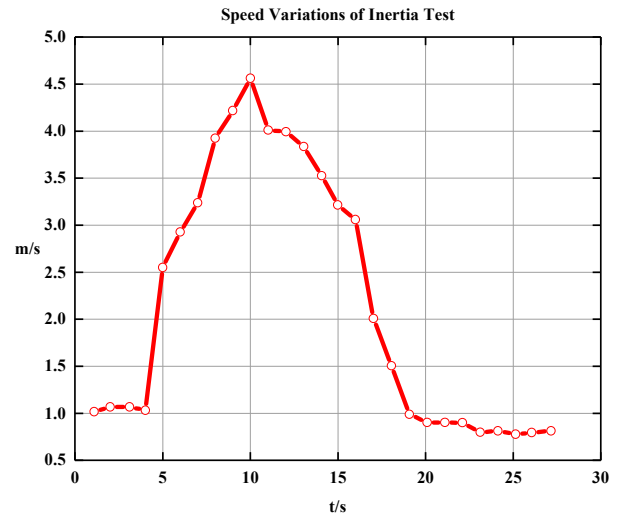

(a)

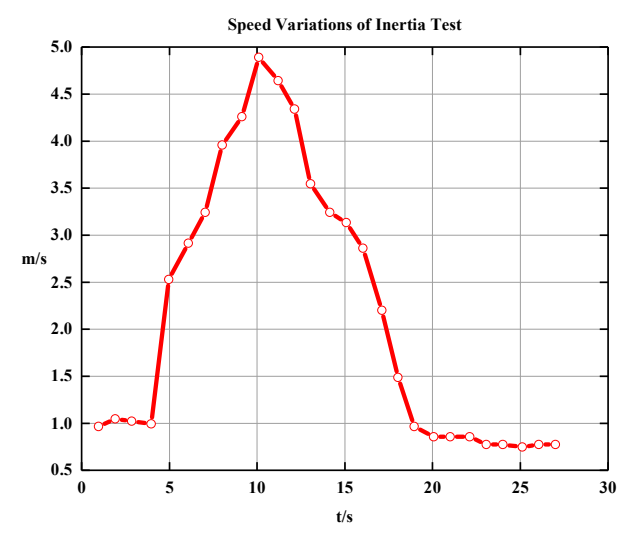

(b)

Figure 5. Velocity curve of inertia test at $\pm 10^{\circ}$ course angle $\left((\mathbf{a}):-10^{\circ}\right.$ course angle; $(\mathbf{b})$ : $10^{\circ}$ course angle)

\subsubsection{Zig-Zag Test}

The $20^{\circ} / 20^{\circ}$ zig-zag test is carried out to validate the maneuverability of the USV, the characteristic test procedures are as follows: (1) first, the USV sails with a certain speed (10 knots $(5 \mathrm{~m} / \mathrm{s})$ of velocity, $3000 \mathrm{r} / \mathrm{min}$ of the pump rotation rate), after a steady approach, steers $20^{\circ}$ to starboard side rapidly, and maintains the rudder angle for $3 \mathrm{~s}$; (2) when the heading angle of the hull is $20^{\circ}$ off the initial course, the rudder is rapidly put over to port side with the same angle of $20^{\circ}$ and hold the helm for $3 \mathrm{~s}$; (3) finally, the test accomplishes until the heading is equal to the initial heading. It should be noted that the variables of the heading angle are recorded at $1 \mathrm{~Hz}$ within the test process.

The rudder response of the USV $20^{\circ} / 20^{\circ}$ zig-zag test is illustrated in Figure 6 , the first overshoot angle is about 20 degrees, which accords with the maneuvering standards-the first overshoot angle in $20^{\circ} / 20^{\circ}$ zig-zag test less than 25 degrees. 


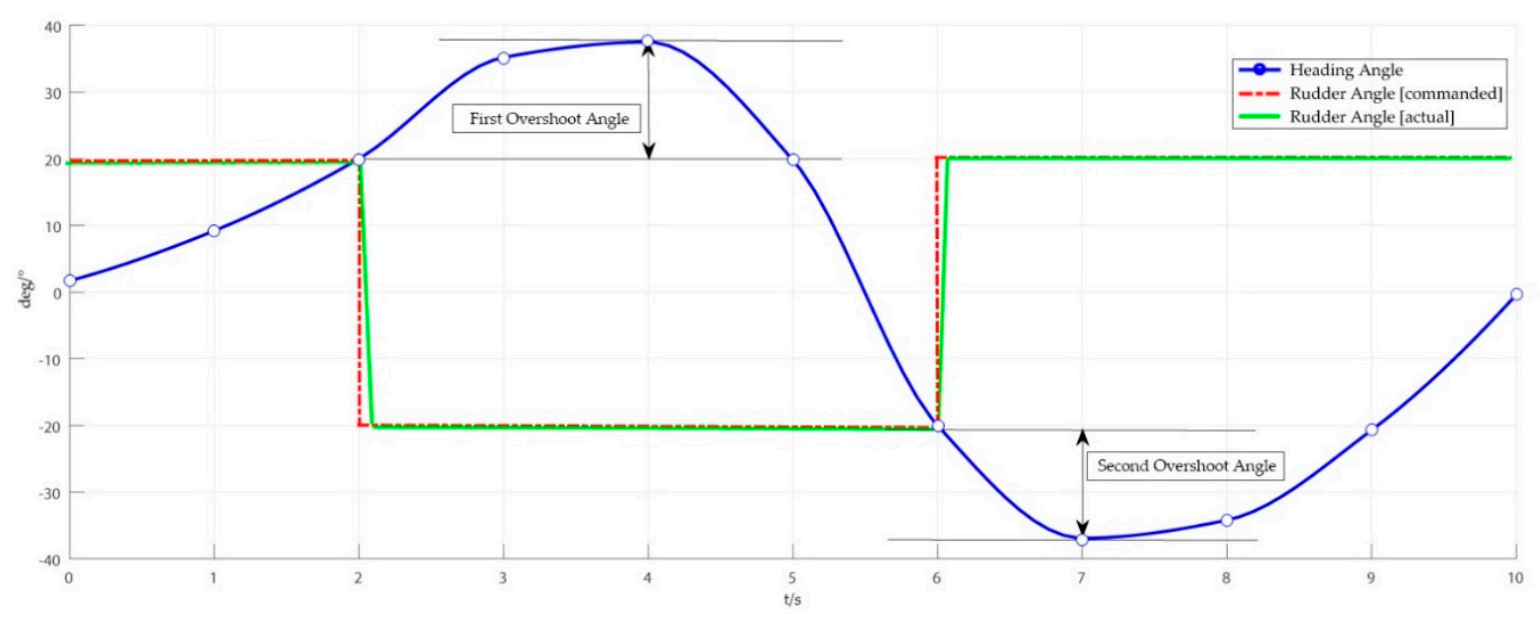

Figure 6. Rudder response of zig-zag test.

\subsubsection{Turning Test}

In the turning test part, the right/left full rudder tests are performed, respectively, the process can be described as: the test starts with a steady straight velocity of 10 knots $(5 \mathrm{~m} / \mathrm{s})$, and then the rudder is turned to the maximum left/right rudder angle permissible, and held up until the USV has performed a turning circle beyond $540^{\circ}$. It is notable that the path of hull is recorded with a time integral of $1 \mathrm{~s}$.

Figure $7 \mathrm{a}, \mathrm{b}$ shows the trajectory of port side and starboard side turning tests, respectively. It could be observed that in port side test, the advance distance (Ad) is $11.5 \mathrm{~m}$, the tactical diameter (DT) is $7.1 \mathrm{~m}$, and in starboard side test, Ad is $14 \mathrm{~m}$ and DT is $3.9 \mathrm{~m}$, which measure up to the maneuverability standards - the Ad of the turning circle less than 4.5 times the Lpp (length of perpendicular) of ship, which can be supposed as the length of all of the USV, namely $3 \mathrm{~m}$; and the DT of the turning circle less than 5 times the Lpp.

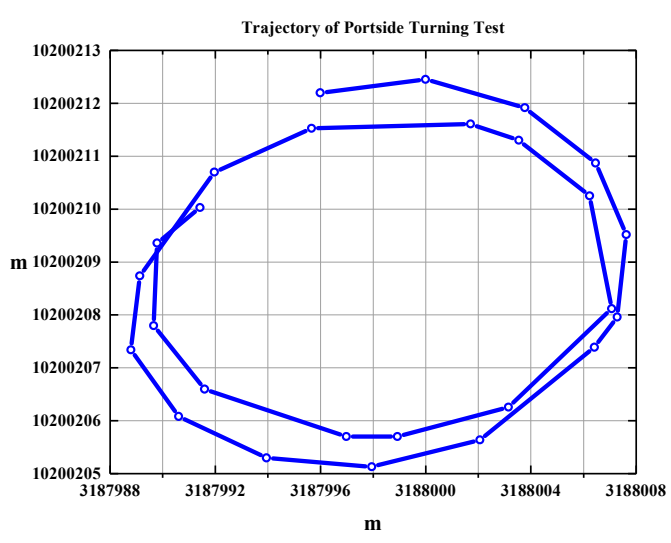

(a)

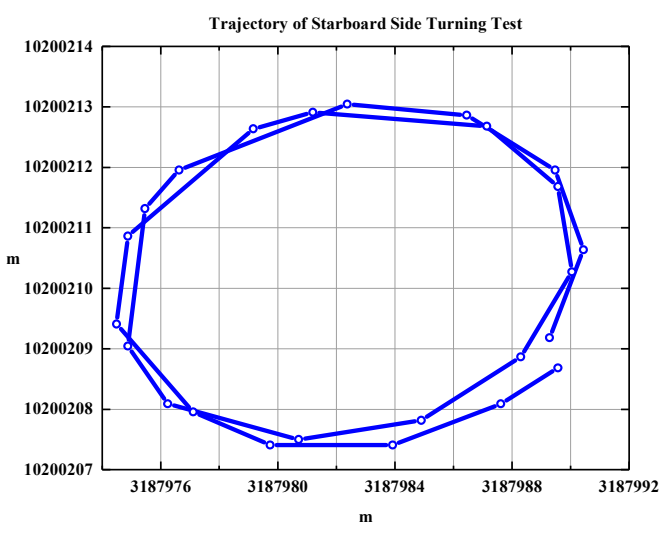

(b)

Figure 7. Path of turning test ((a): port; (b): starboard).

\subsubsection{Discussion}

It can be concluded that through the inertia test, the $20^{\circ} / 20^{\circ}$ zig-zag test and turning tests, the results are generally acceptable for engineering application.

(1) Results in Figure 5 indicate that the USV has a good speed regulating ability, and good maneuverability with less than 10 times of LOA in both positive directions stopping test and $\pm 10^{\circ}$ heading direction stopping tests. 
(2) Figure 6 illustrates the rudder response of the USV in the $20^{\circ} / 20^{\circ}$ zig-zag test, the first and second overshoot angles are about 20 degrees, which accords with the maneuvering standards.

(3) From Figure 7a,b, it can be seen that in port side test of turning tests, the advance distance (Ad) is $11.5 \mathrm{~m}$, the tactical diameter (DT) is $7.1 \mathrm{~m}$, and in starboard side test, Ad is $14 \mathrm{~m}$ and DT is $3.9 \mathrm{~m}$, which measure up to the maneuverability standards.

(4) It can be concluded from results of the maneuvering tests, that the USV has good maneuverability and the performance is generally acceptable for engineering application.

\subsection{HSIC Control}

In the above tests, the output of the controller is a rudder angle, which controls the speed variance of the rotation speed of the motors $n_{1}$ and $n_{2}$ to realize the steering of USV. However, for the purpose of increasing mission efficiency and achieving the motion goals of the USVs in a dynamic sailing environment [27], researchers now utilize the Human Simulated Intelligent Control (HSIC) to study complex and uncertain systems, the flow chart of Human Simulated Intelligent Control is shown in Figure 8. The current navigation state of the ship corresponds to the control deviation, and the movement trend corresponds to the deviation change rate. The model of HSIC can be expressed as Equation (8)

$$
U=\left\{\begin{array}{c}
k \cdot K_{p} \sum_{i=1}^{n-1} e_{m, i}+K_{p} e(e \cdot e>0 \cup e=0 \cap e \neq 0) \\
k \cdot K_{p} \sum_{i=1}^{n} e_{m, i}(e \cdot e<0 \cup e=0)
\end{array}\right.
$$

where, $U$ is the controller output; $K_{P}$ is the proportional gain coefficient of the controller; $k$ is the suppression factor of the controller $(0 \leq k \leq 1)$; $e$ is the systematic error; $e$ is the error rate of change $e_{m, i}$ is the extremum of error. In actual navigation, the USV control system abides the following steps, $K_{P}, K_{d}, K_{i}$ coefficients are values for determining the effect of particular terms on the automatic process control.

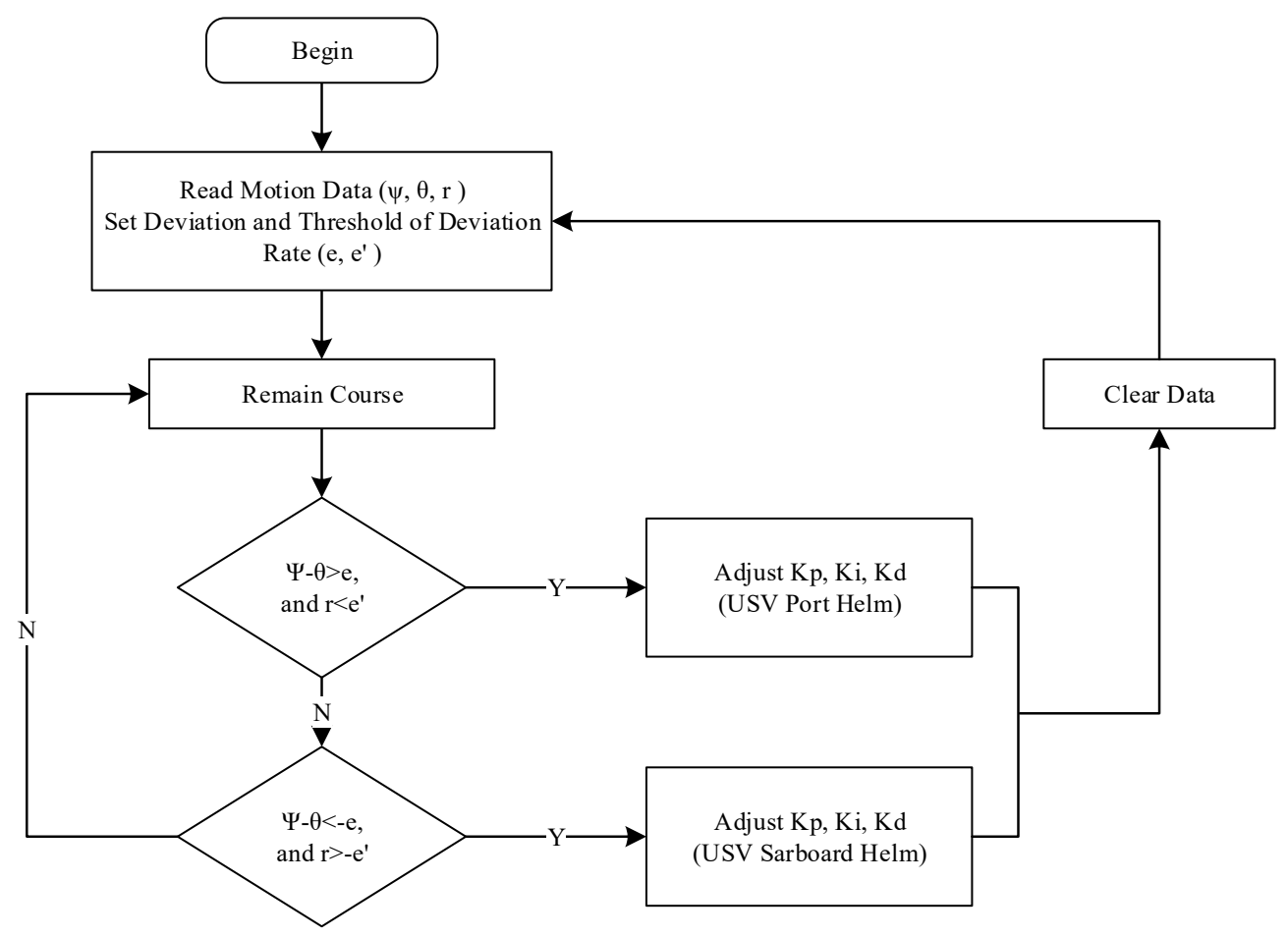

Figure 8. Flow chart of Human Simulated Intelligent Control (HSIC); $\theta$ is the azimuth angle, ${ }^{\circ} ; r$ is the yaw rate, $\mathrm{rad} / \mathrm{s} ; e^{\prime}$ is the error change rate. 
Based on the experiment data in Table 4, the relationship between control variables (rudder angle) and state variables (course) can be determined. In this simulation test, the threshold of deviation and variation rate of deviation are set to $e_{1}=5, e_{1}=5, e_{2}=5, e_{2}=5$.

Table 4. Mapping relation of rudder angle and rotation speed n1 and n2.

\begin{tabular}{ccccc}
\hline Rudder Angle & $\begin{array}{c}\text { Left Pump Rotational Speed } \\
\boldsymbol{n}_{\mathbf{1}}-\mathbf{R i g h t} \text { Pump Rotational Speed } \boldsymbol{n}_{\mathbf{2}} \\
\mathbf{( 0 - 2 5 0 0} \mathbf{r} / \mathbf{m i n})\end{array}$ & $\boldsymbol{K}_{\boldsymbol{P i}}$ & $\boldsymbol{K}_{\boldsymbol{d i}}$ & $\boldsymbol{K}_{\boldsymbol{i i}}$ \\
\hline $5^{\circ}$ & $1625 \mathrm{r} / \mathrm{min}-1500 \mathrm{r} / \mathrm{min}$ & 765 & 0.3 & 100 \\
$10^{\circ}$ & $1775 \mathrm{r} / \mathrm{min}-1500 \mathrm{r} / \mathrm{min}$ & 1275 & 0.5 & 100 \\
$15^{\circ}$ & $1950 \mathrm{r} / \mathrm{min}-1500 \mathrm{r} / \mathrm{min}$ & 1530 & 0.6 & 100 \\
$20^{\circ}$ & $2150 \mathrm{r} / \mathrm{min}-1500 \mathrm{r} / \mathrm{min}$ & 2040 & 0.8 & 100 \\
$-5^{\circ}$ & $1950 \mathrm{r} / \mathrm{min}-2200 \mathrm{r} / \mathrm{min}$ & 765 & 0.3 & 100 \\
$-10^{\circ}$ & $1775 \mathrm{r} / \mathrm{min}-2200 \mathrm{r} / \mathrm{min}$ & 1275 & 0.5 & 100 \\
$-15^{\circ}$ & $1625 \mathrm{r} / \mathrm{min}-2200 \mathrm{r} / \mathrm{min}$ & 1530 & 0.6 & 100 \\
$-20^{\circ}$ & $1550 \mathrm{r} / \mathrm{min}-2200 \mathrm{r} / \mathrm{min}$ & 2040 & 0.8 & 100 \\
\hline
\end{tabular}

To satisfy the accuracy level and make the control effect serve the purpose of practice, the control coefficient $k_{p}, k_{i}$ and $k_{d}$ in the PID controller are modified. The control effect is optimal when $k_{p}=1200$, $k_{d}=0.74, k_{i}=75$ among pre-experiments. Selecting $45^{\circ}, 90^{\circ}, 135^{\circ}$ and $180^{\circ}$ east-north course angles as the input response of unit-step signal, simulations are conducted to compare the control effects of the PID controller and HSIC, and the result is shown in Figure 9. The result indicates the HSIC controller is better than the PID controller, and the HSIC controller has a better speed of response, smaller overshoot and shorter time to reach a steady state than the PID. When the target input of the controlled object changes, the HSIC controller can still ensure that the controlled process is monotonous, with no overshoot and no static error.

(a)

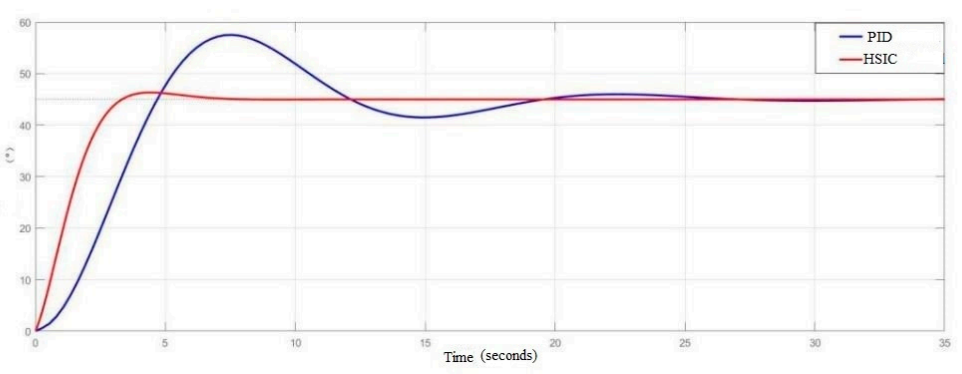

(b)

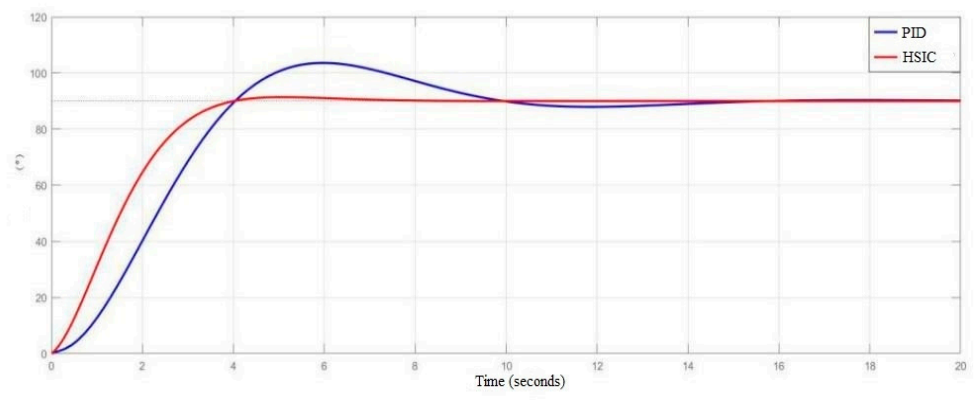

Figure 9. Cont. 
(c)

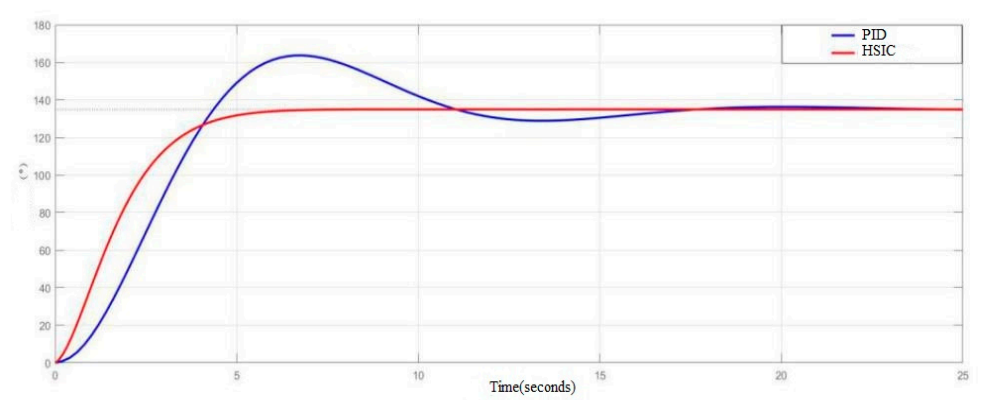

(d)

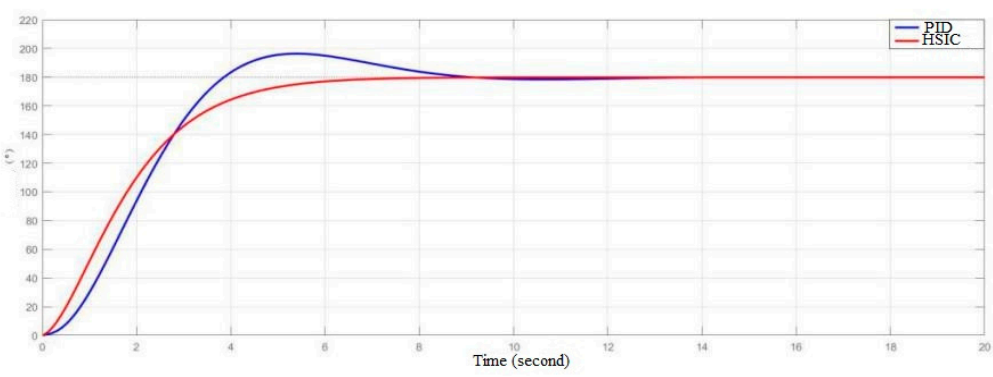

Figure 9. Target course control comparison test $\left((\mathbf{a}): 45^{\circ} ;(\mathbf{b}): 90^{\circ} ;(\mathbf{c}): 135^{\circ} ;(\mathbf{d}): 180^{\circ}\right)$.

\subsection{System Simulation Test}

After validating the performance of the motion control based on HSIC method through simulation tests, full-scale USV tests are carried out to validate the practicability of the control algorithm. The specific procedures are as follow: two target points are set up through the host computer control platform, starting point ' $\mathrm{O}$ ' and terminal point of reversal ' $\mathrm{S}$ ', which form a straight sailing course with an azimuth of $200^{\circ}$ north by east. The USV would sail to the starting point ' $\mathrm{O}$ ' (deviation of the radius less than $7 \mathrm{~m}$ ), then automatically adjust the heading angle to target course with a threshold error of $\pm 5^{\circ}$, and sail straight to the terminal point. The system acquiesces the USV accomplishes reversal when the USV reaches the area around the terminal point within a $5 \mathrm{~m}$ radius, and by then the USV executes stop command. The results of the test are shown in Figure 10, where the length of direction-maintaining control test is $22.2245 \mathrm{~m}$, speed of USV is 7 knots $(3.5 \mathrm{~m} / \mathrm{s})$, the error of path is under $1 \mathrm{~m}$, error of course angle is under $2^{\circ}$.

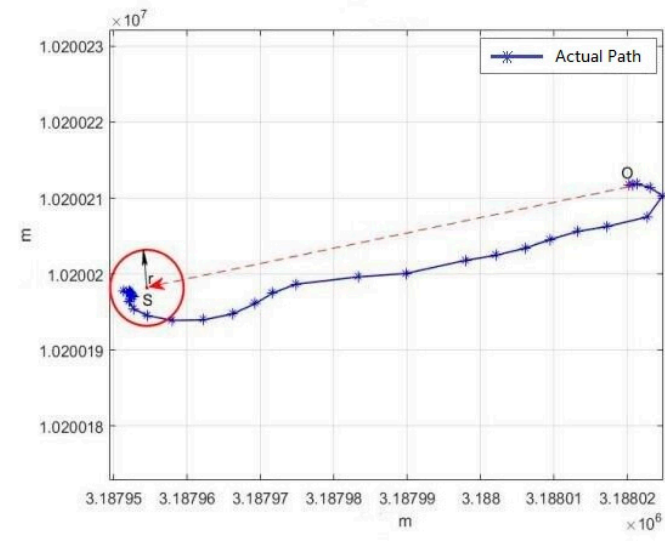

(a)

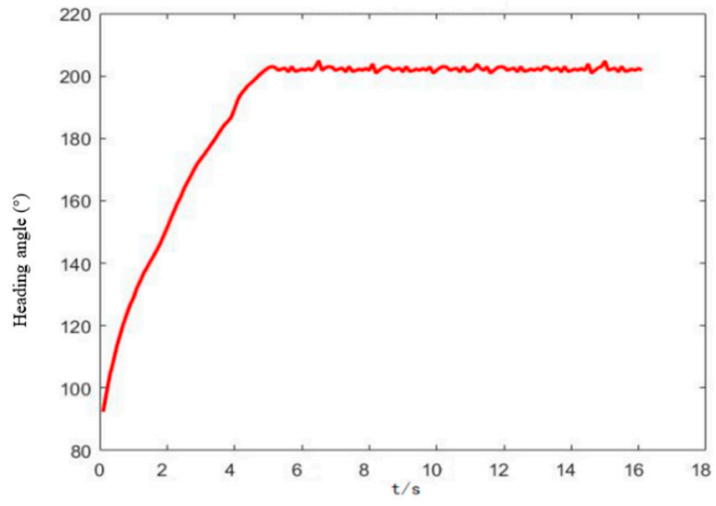

(b)

Figure 10. Result of full-scale USV test ((a): return path; (b): $200^{\circ}$ direction-preserving angle time-varying curve). 


\subsection{Path Following of USV}

The precise path following during maneuvering is very important [28], especially for autonomous water platform, the control logic of which can be divided into two parts of algorithm: the upper is the navigation algorithm based on LOS, and the underlying is a motion control algorithm based on the HSIC method. This method is a supplement to the Serret-Frenet frame under the situations of high speed and large turning angles, while in other cases, it is consistent with the Serret-Frenet frame.

\subsubsection{Path Correction}

As shown in Figure 11, $h_{k}$ is the vertical distance between the current position $(P)$ and the set route, $\mathrm{m} ; h_{k+1 / k}$ illustrates the vertical distance at $k+1, \mathrm{~m} ; \psi_{k}$ is the current heading angle, ${ }^{\circ} ; v_{k}$ is the velocity, $\mathrm{m} / \mathrm{s}$.

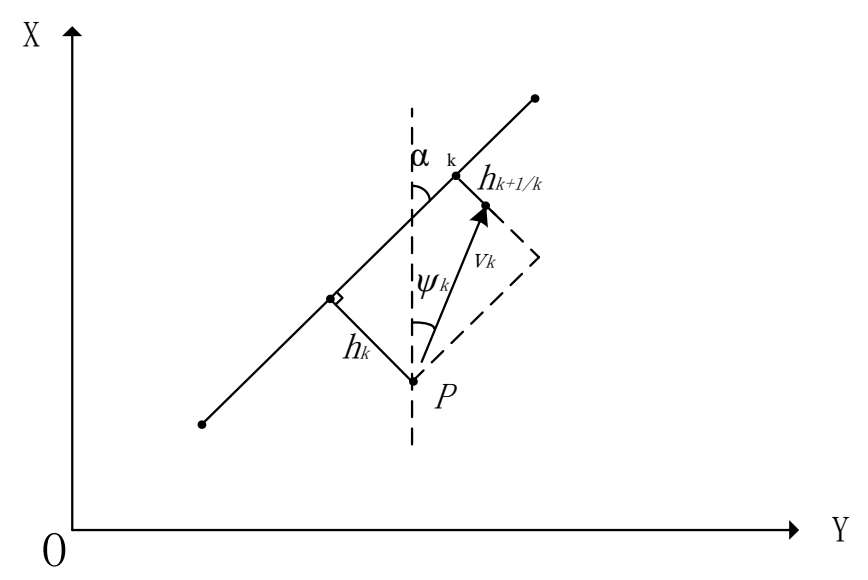

Figure 11. Path correction.

Through analyzing, when the sampling period is $\Delta t$,

$$
\alpha_{k}=\psi_{k}+\arcsin \left(\frac{h_{k}-h_{k+1 / k}}{v_{k} \Delta t}\right)
$$

when $\frac{h_{k}-h_{k+1 / k}}{v_{k} \Delta t} \rightarrow 0$, Equation (9) becomes

$$
h_{k+1 / k}=h_{k}-\left(\alpha_{k}-\psi_{k}\right) \cdot v_{k} \Delta t
$$

If the heading changes,

$$
\Delta \psi=\frac{\Delta h_{k+1 / k}}{v_{k} \Delta t}
$$

where, $\Delta h_{k+1 / k}$ is to predict the change of track deviation at the next time, $\mathrm{m}$. According to Equation (10) and the K-T equation,

$$
\delta_{k+1}=\frac{\Delta h_{k+1 / k}}{K v_{k}\left(1-e^{-\frac{\Delta t}{T}}\right) \Delta t^{2}}
$$

where, $\delta_{k+1}$ is the target rudder angle for control, ${ }^{\circ} ; K$ is the turning ability index, $T$ is the turning lag index. The purpose of path correction can be achieved by predicting the path deviation variation at the next moment and outputting the specified rudder angle value correspondingly. By looking up the data in Table 1, the speed of the motor can be controlled to rectify the path deviation.

\subsubsection{Steering Point Control}

As shown in Figure 12, $P$ is the current position, and $P$ is at the outer circle boundary of the steering control area. $L_{p}$ is the distance between $P$ and the next turning point $P_{k+1}, \mathrm{~m}$. Make the vertical 
line of $\overline{P_{k} P_{k+1}}$ through $P$, and intersect with $P_{h} . h_{p}$ is the current track deviation, $\mathrm{m} . \angle P_{t 1} P_{o} P=\theta$, $\angle P_{t 1} P_{o} P_{k+1}=\angle P_{t 2} P_{0} P_{k+1}=\alpha$ and $\angle P_{k} P_{k+1} P_{k+2}=2 \beta$ are the constraint boundary. $P_{o}$ is the center of a circle with radius $r_{p}$ passing through $P$, and is tangent to $P_{t 1}$ and $P_{t 2}$. If the USV turns in light of the expected turning radius $r_{p}$, the ideal path line will be tangent to the two expected routes $\overline{P_{k} P_{k+1}}$ and $\overline{P_{k+1} P_{k+2}}$, then the relatively stable turning be can be achieved.

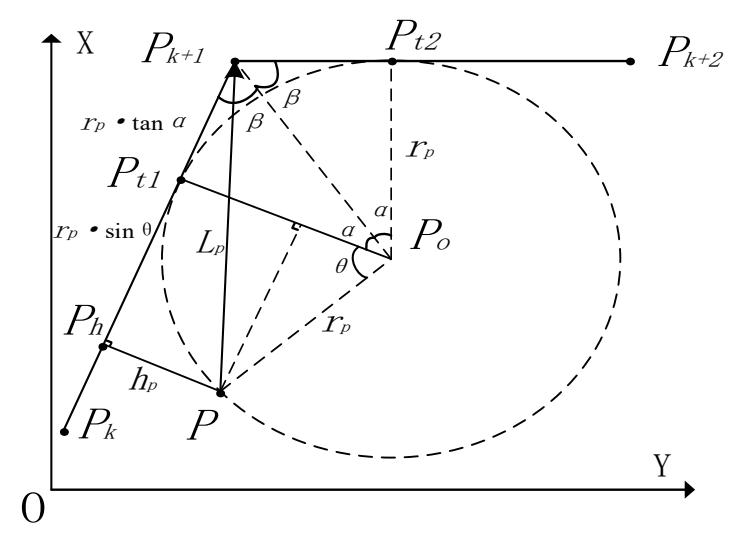

Figure 12. Steering point control.

It can be seen from the above figure,

$$
\left\{\begin{array}{c}
r_{p} \cos \theta=r_{p}-h_{p} \\
r_{p} \sin \theta=\sqrt{L_{p}^{2}-h_{p}^{2}}-r_{p} \tan \alpha
\end{array}\right.
$$

where, $\alpha=\frac{\pi}{2}-\beta$, let $l=\sqrt{L_{p}^{2}-h_{p}^{2}}\left(l\right.$ is $\left.\overline{P_{h} P_{k+1}}\right)$, Equation (13) can be changed to:

$$
\tan ^{2} \alpha \cdot r_{p}^{2}-2\left(h_{p}+l \tan \alpha\right) r_{p}+L_{p}^{2}=0
$$

let $A=\tan ^{2} \alpha, B=-2(h+l \tan \alpha), C=L_{p}^{2}$, then

$$
\left\{\begin{array}{l}
r_{p 1}=\frac{-B+\sqrt{B^{2}-4 A C}}{2 A} \\
r_{p 2}=\frac{-B-\sqrt{B^{2}-4 A C}}{2 A}
\end{array}\right.
$$

there will be many solutions in Equation (15), as shown in Figure 13.

(1) When $\angle P_{k} P_{k+1} P_{k+2}=2 \beta>90, r_{p}=r_{p 1}$;

(2) When $\angle P_{k} P_{k+1} P_{k+2}=2 \beta=90, r_{p}=r_{p 1}=r_{p 2}=-\frac{B}{2 A}$;

(3) When $\angle P_{k} P_{k+1} P_{k+2}=2 \beta<90, r_{p}=r_{p 2}$.

The sampling period $\Delta t=1 \mathrm{~s}$, the velocity is $5-10$ knots $(2.5-5 \mathrm{~m} / \mathrm{s})$, through Table 1 , the speed of the motor can be controlled to achieve stable steering. 


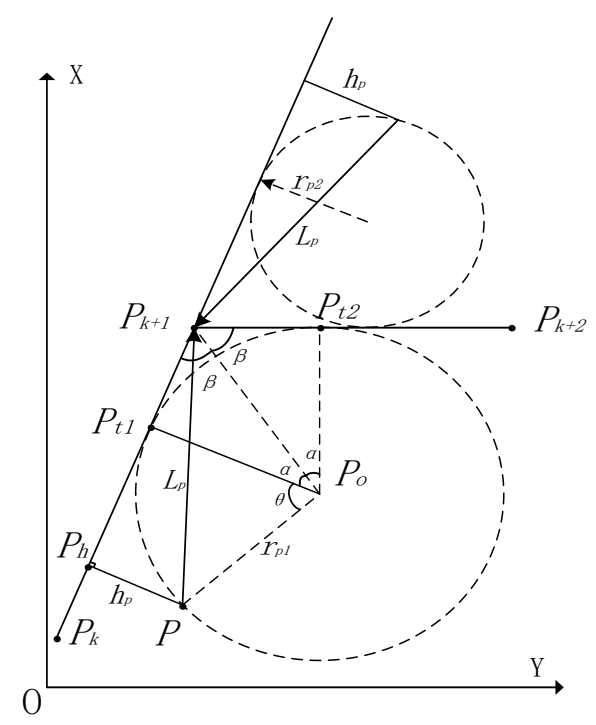

Figure 13. Multi solution problem of turning point control.

\subsubsection{Experiments of Multi-Point Path Following}

After the improvement of path correction and steering point control of the LOS algorithm, combined with the USV control system, the principle of path following program is shown in Figure 14. To verify the applicability of the algorithm, a triangular path test, and a square path test were carried out.

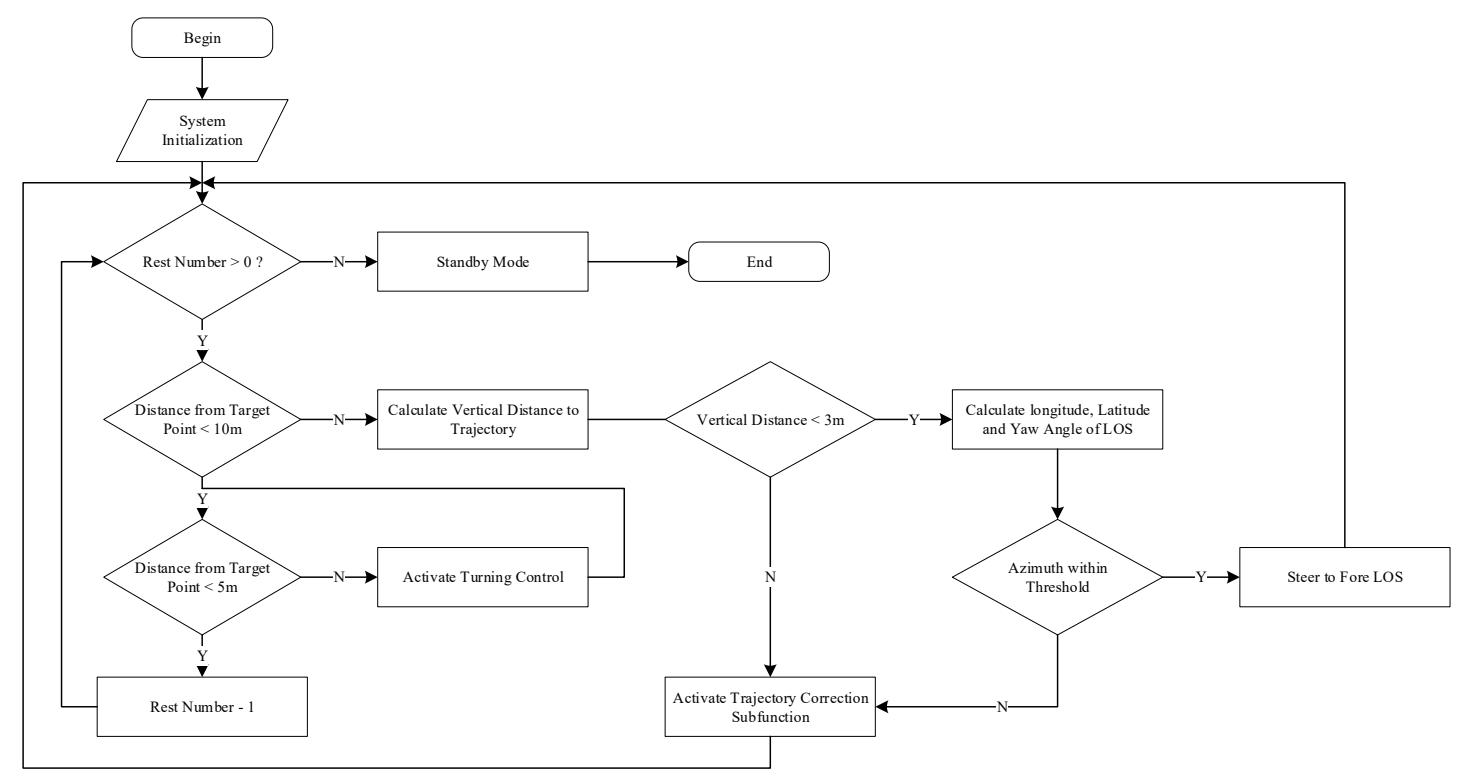

Figure 14. Flow chart of path following algorithm.

Triangle Path Test

The results of the triangle path test before and after the improvement of the control program are shown in Figure 15. Before the triangle path test, the path length of the path is $120.8610 \mathrm{~m}$, maximum path error is up to $8 \mathrm{~m}$, the average error is $3.2 \mathrm{~m}$. After the improvement, the maximum error is modified to $3.6 \mathrm{~m}$, and the average error is $1.8 \mathrm{~m}$. So, the improved algorithm has a higher path following accuracy. 
(a)

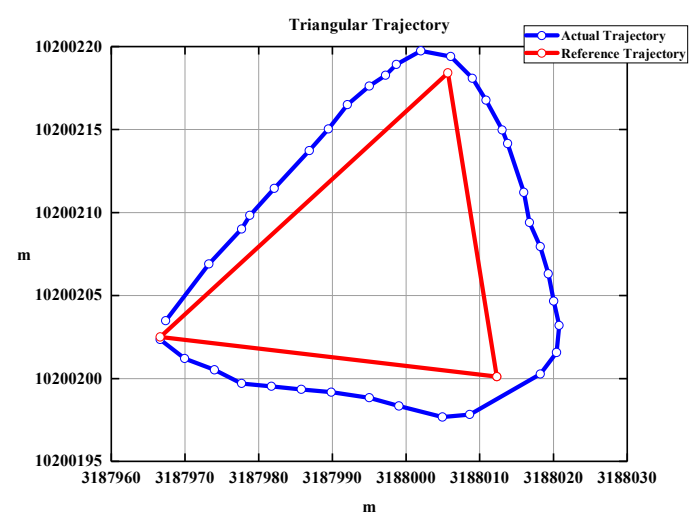

(b)

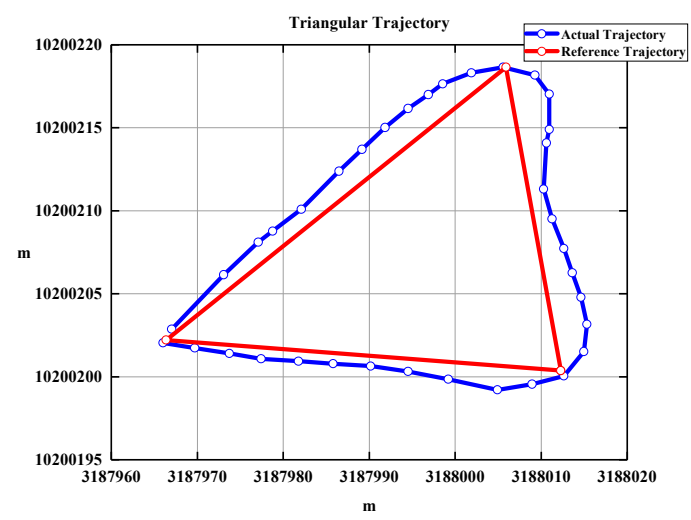

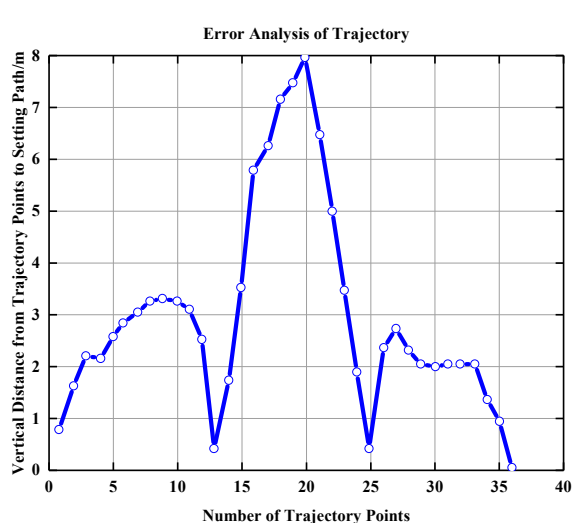

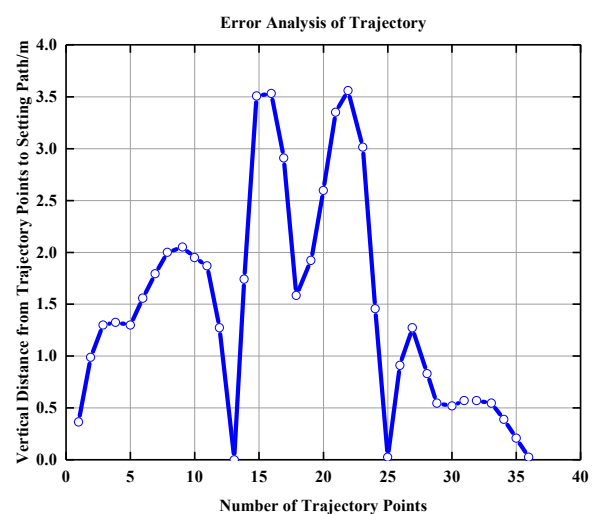

Figure 15. Triangle path test and error analysis ((a): before improvement; (b): after improvement).

\section{Square Path Test}

The results of the square path test before and after the improvement of the control program are shown in Figure 16. Before the square path test, the path length of the path is $151.840 \mathrm{~m}$, maximum path error is up to $4.9 \mathrm{~m}$, the average error is $3.5 \mathrm{~m}$. After the improvement, the maximum error is modified to $3.8 \mathrm{~m}$, and the average error is $1.5 \mathrm{~m}$. Thus, the improved algorithm has a higher path following accuracy.

(a)

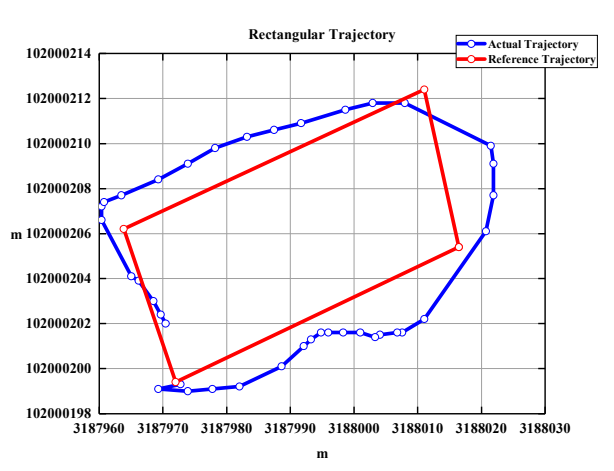

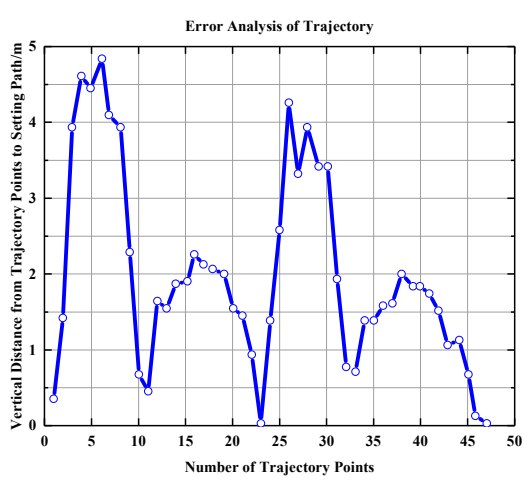

Figure 16. Cont. 
(b)
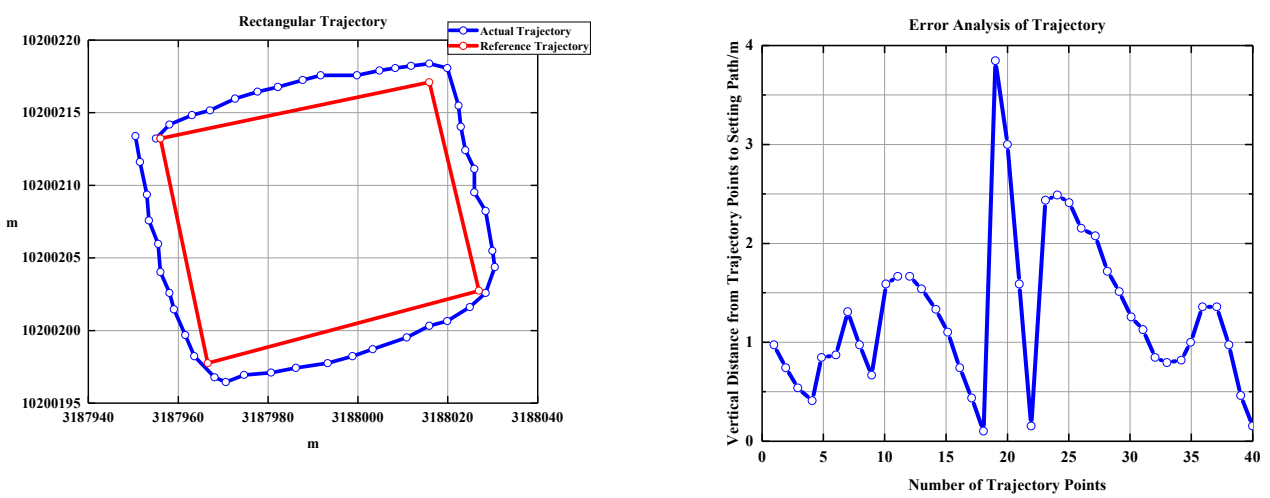

Figure 16. Square Path Test and Error Analysis ((a): before improvement; (b): after improvement).

\subsubsection{Discussion}

In order to solve the problem of path correcting and steering point controlling, the LOS algorithm has been improved. Combined with the system network control method, the path following experiments of triangle and square path tests are carried out, and the errors of path following before and after the improvement are compared, which proves that the improved algorithm has higher path following accuracy.

Limited by the experimental conditions, the tests in this paper are carried out in a still water tank. Considering that in real sea conditions, the USV will be affected by wind, wave, current and other environmental disturbances, they can be regarded as external forces and added to the mathematical model by randomly combined cosine functions, which would lay the foundation for the application of the algorithms.

\section{Conclusions}

Complete modeling, and control design for maneuvering a twin water-jetted USV along the desired path has been presented. The maneuvering procedure with tests have proved that the control system platform with intelligent navigation algorithm can improve the motion control and path following of the USV. The detailed works include:

(1) A 3-DOF mathematical model of the USV was established, an integrated control system was designed and verified through maneuvering tests, for instance, inertia tests, zig-zag test and turning tests. The results show that the twin water-jetted USV has good maneuverability, and follow-up researches can be carried out based on this hull;

(2) The HSIC algorithm was designed, and the comparative test of heading control was carried out. The reliability of the algorithm was verified by real ship experiments;

(3) The Line of Sight (LOS) algorithm was improved to realize the USV on the set route. Autonomous navigation path following and track rectification were realized, and experimental verification (triangle/square path test) of the practicability of the algorithm were carried out.

In future research, the influence of wind, wave, current, and other environmental disturbance factors should be taken into account. In the path planning experiments, the problems of obstacles and autonomous collision avoidance need to be considered. In addition, to increase the stability and reliability of the control system, it is necessary to optimize the multi-sensors fusion of USV.

Author Contributions: Conceptualization, J.M., Y.H. and Y.X.; formal analysis, Y.H., B.Z. and S.L.; data curation, Y.H., B.Z. and S.L.; writing-original draft preparation, Y.H.; writing-review and editing, J.M. and Y.X.; supervision, J.M. All authors have read and agreed to the published version of the manuscript. 
Funding: The work presented in this paper is financially supported by National Natural Fund of China (Grant number 51579201), Independent innovation fund for graduate students of Wuhan University of Technology (Grant number 195212002), the Open Foundation of Nation Water Transportation Safety Engineering Technical Center (Grant number: 17KF02) and the Transportation Science and Technology Project of Jiangsu Province (2018Z01).

Conflicts of Interest: The authors declare no conflict of interest.

\section{References}

1. Wang, Y. Concepts of waterjet propulsion and pumpjet propulsion: Their common characteristics, special characteristics and differences. Chin. J. Ship Res. 2019, 14, 1-9,41.

2. Liu, Q.; Wang, Y.; Yang, Q.; Cheng, X. Design and Implementation of an Electric Propulsion System for Small Unmanned Surface Vehicle. Meas. Control Technol. 2016, 35, 71-74.

3. Naeem, W.; Xu, T.; Sutton, R.; Tiano, A. The design of a navigation, guidance, and control system for an unmanned surface vehicle for environmental monitoring. Proc. Inst. Mech. Eng. M 2008, 222, 67-79. [CrossRef]

4. Liu, Z.; Zhang, Y.; Yu, X.; Yuan, C. Unmanned surface vehicles: An overview of developments and challenges. Annu. Rev. Control 2016, 41, 71-93. [CrossRef]

5. Yang, W.; Chen, C.; Hsu, C.; Tseng, C.; Yang, W. Multifunctional Inshore Survey Platform with Unmanned Surface Vehicles. Int. J. Autom. Smart Technol. 2011, 1, 19-25. [CrossRef]

6. Yan, R.; Pang, S.; Sun, H.; Pang, Y. Development and missions of unmanned surface vehicle. J. Mar. Sci. Appl. 2010, 9, 451. [CrossRef]

7. Motwani, A. A survey of uninhabited surface vehicles. In Marine and Industrial Dynamic Analysis; Technical Report; Plymouth University: Plymouth, UK, 22 April 2012.

8. Manley, J.E.; Marsh, A.; Cornforth, W.; Wiseman, C. Evolution of the autonomous surface craft AutoCat. In Proceedings of the OCEANS 2000 MTS/IEEE Conference and Exhibition. Conference Proceedings (Cat. No. 00CH37158), Providence, RI, USA, 11-14 September 2000; Volume 1, pp. 403-408.

9. Bertram, V. Unmanned Surface Vehicles-A Survey; Skibsteknisk Selskab: Copenhagen, Denmark, 2008; pp. 1-14.

10. Lin, L.; Zhang, B. Technical Development and Operational Application of Unmanned Surface Combat System. J. Unmanned Undersea Syst. 2018, 26, 107-114.

11. Peng, Y.; Yang, Y.; Cui, J.; Li, X.; Pu, H.; Gu, J.; Xie, S.; Luo, J. Development of the USV 'JingHai-I' and sea trials in the Southern Yellow Sea. Ocean Eng. 2017, 131, 186-196. [CrossRef]

12. Specht, M.; Specht, C.; Lasota, H.; Cywinski, P. Assessment of the Steering Precision of a Hydrographic Unmanned Surface Vessel (USV) along Sounding Profiles Using a Low-Cost Multi-Global Navigation Satellite System (GNSS) Receiver Supported Autopilot. Sensors 2019, 19, 3939. [CrossRef] [PubMed]

13. Villa, J.L.; Paez, J.; Quintero, C.; Yime, E.; Cabrera, J. Design and control of an unmanned surface vehicle for environmental monitoring applications. In Proceedings of the 2016 IEEE Colombian Conference on Robotics and Automation (CCRA), Bogota, Colombia, 29-30 September 2016; pp. 1-5.

14. Haraguchi, T. Simple estimation method on ship manoeuvrability by means of manoeuvring performance database. MARSIM 2000 2000, 2000, 289-300.

15. Li, L.; Zhu, Q.D.; Gao, S.; Wang, J. Maneuvering Capability Simulation and Analysis for Twin Waterjet-propelled Vessel. J. Syst. Simul. 2008, 20, 3104-3106.

16. Huang, X. Study on Unmanned Surface Vehicle Modeling and Simulation of Manipulation Movement. Master's Thesis, Dalian Maritime University, Dalian, China, 2015.

17. Ma, T. Research on the Maneuverability of a New Type Unmanned Surface Vehicle and its Cooperative Strategy. Master's Thesis, Jiangsu University of Science and Technology, Zhenjiang, China, 2015.

18. Zhang, Y. Mathematical Characteristic of Human Intelligent PID and Simulation in Application. Electron. World 2018, 21, 108.

19. Hu, J. Research on Unmanned Ship Autopilot System Based on Human Simulated Intelligent Control. Ship Sci. Technol. 2017, 39, 46-48.

20. Zha, Z.; Yang, Z.; Feng, D. Control strategy on human simulated intelligence in complex system. J. Shaanxi Univ. Sci. Technol. 2006, 24, 57-62. 
21. Yang, Y.; Li, Q.; Zhang, J.; Xie, Y. Iterative Learning-Based Path and Speed Profile Optimization for an Unmanned Surface Vehicle. Sensors 2020, 20, 439. [CrossRef] [PubMed]

22. Singh, Y.; Sharma, S.; Sutton, R.; Hatton, D. Optimal Path Planning of an Unmanned Surface Vehicle in a RealTime Marine Environment using a Dijkstra Algorithm. In Marine Navigation and Safety of Sea Transportation. Proceedings of the TransNav2017, Gdynia, Poland, 21-23 June 2017; CRC Press: Boca Raton, FL, USA, 2017; pp. 399-402.

23. Fossen, T.I. Handbook of Marine Craft Hydrodynamics and Motion Control; John Wiley \& Sons: Hoboken, NJ, USA, 2011.

24. Liu, T.; Dong, Z.; Du, H.; Song, L.; Mao, Y. Path following control of the underactuated USV based on the improved line-of-sight guidance algorithm. Nephron Clin. Pract. 2017, 24, 3-11. [CrossRef]

25. Caharija, W.; Candeloro, M.; Pettersen, K.Y.; Sørensen, A.J. Relative Velocity Control and Integral LOS for Path Following of Underactuated Surface Vessels. IFAC Proc. Vol. 2012, 45, 380-385. [CrossRef]

26. Lekkas, A.M.; Fossen, T.I. Integral LOS Path Following for Curved Paths Based on a Monotone Cubic Hermite Spline Parametrization. IEEE Trans. Control Syst. Technol. 2014, 22, 2287-2301. [CrossRef]

27. Bibuli, M.; Singh, Y.; Sharma, S.; Sutton, R.; Hatton, D.C.; Khan, A. A Two Layered Optimal Approach towards Cooperative Motion Planning of Unmanned Surface Vehicles in a Constrained Maritime Environment. IFAC-PapersOnLine 2018, 51, 378-383. [CrossRef]

28. Stateczny, A.; Burdziakowski, P.; Najdecka, K.; Domagalskastateczna, B. Accuracy of Trajectory Tracking Based on Nonlinear Guidance Logic for Hydrographic Unmanned Surface Vessels. Sensors 2020, $20,832$. [CrossRef] [PubMed]

(C) 2020 by the authors. Licensee MDPI, Basel, Switzerland. This article is an open access article distributed under the terms and conditions of the Creative Commons Attribution (CC BY) license (http://creativecommons.org/licenses/by/4.0/). 